\title{
TEATER WANGI JADI SAKSI: SATU BACAAN SEMULA TERHADAP SEJARAH SETIA KAWAN TUAH-JEBAT
}

\section{(Wangi Jadi Saksi: A Historical Re-reading of the Kinship between Tuah-Jebat )}

Wan Hasmah Wan Teh

hasmahwt@usm.my

Pusat Pengajian Ilmu Kemanusiaan, Universiti Sains Malaysia, Malaysia.

\begin{abstract}
Abstrak
Kisah Hang Tuah dan Hang Jebat dalam teks klasik Sulalat al-Salatin dan Hikayat Hang Tuah telah menjadi ilham kepada pembuat filem, teater dan pencipta lagu. Filem pertama yang menonjolkan Tuah-Jebat secara audio visual bertajuk Hang Tuah ditayangkan pada tahun 1956 di bawah arahan Phani Majumdar, kemudiannya diikuti oleh filem bertajuk Hang Jebat oleh Hussein Hanif pada tahun 1961. Biarpun dua filem ini adalah antara adaptasi terawal yang menghidupkan watak Tuah-Jebat di layar perak, namun sudah terkesan terdapat kecenderungan tertentu ketika memfilemkannya. Kedua-dua watak ini tampil dengan bacaan dan interpretasi yang berbeza oleh keduadua pengarah filem terdahulu. Hal ini tidak dapat dielakkan untuk sebuah filem, drama mahupun teater adaptasi. Tafsiran atau interpretasi semula ialah bahan kreatif seseorang pengarah ketika melakukan adaptasi. Menerusi teater arahan dan skrip oleh U-Wei Haji Saari, kita sekali lagi diingatkan tentang kisah setia kawan Tuah-Jebat dalam Wangi Jadi Saksi. Wangi ditampilkan sebagai saksi mata dan penyimpan rahsia kepada peristiwa pertikaman dua sahabat yang menjadi legenda dalam masyarakat Melayu. Makalah ini akan menjelaskan makna adaptasi dan kesesuaian interpretasi dan bacaan semula U-Wei terhadap kisah pertikaman tersebut melalui watak Wangi dengan memanfaatkan kerangka teori intertekstualiti. Makalah ini mendapati, dalam usaha U-Wei memberikan tafsiran terhadap peristiwa pertikaman Tuah-Jebat,
\end{abstract}


beliau sebenarnya telah mencipta satu teks baharu dengan meruntuhkan kenyataan yang sudah diterima masyarakat berabad-abad lamanya.

Kata kunci: Hang Tuah, Hang Jebat, U-Wei, adaptasi, interpretasi semula

\begin{abstract}
The story of Hang Tuah and Hang Jebat in the classical texts Sulalat al-Salatin and Hikayat Hang Tuah has been a source of inspiration to filmmakers, theatre directors and songwriters. The first audio-visual film that projected the solidarity of Tuah-Jebat in 1956 was titled Hang Tuah under the direction of Phani Majumbar. This was then followed by the film Hang Jebat directed by Hussein Hanif in 1961. Although these two films were among the earliest adaptations that resurrected the characters of Tuah-Jebat on the big screen, however, it was evident that the films had shown certain inclinations during the filming process. This is inevitable for a film, drama or theatrical adaptation. In an adaptation, differences in reading or interpretation are a normal occurrence; they reflect a director's personal creativity in the adaptation process. U-Wei Haji Saari reminds us of this process by bringing new light to the story of the two legendary figures through his work "Wangi Jadi Saksi". In particular, the work features the character Wangi, who is a witness and a secret keeper to the fight between two friends, touted as legendary in Malay society. This paper aims to explain the concept of adaptation and the relevant interpretation in U-Wei Haji Saari's rereading of the stabbing incident through the character of Wangi guided by an intertextual framework. It argues that U-Wei Saari, in his reinterpretation of the stabbing between Tuah and Jebat, has actually created a new text, which challenges views regarding the relationship between Tuah and Jebat which has been accepted by society for many centuries.
\end{abstract}

Keywords: Hang Tuah, Hang Jebat, U-Wei, adaptation, re-interpretation

\title{
PENGENALAN
}

Hang Tuah merupakan wira agung bangsa Melayu yang amat setia kepada rajanya. Apabila berbicara tentang Hang Tuah, kita tentu tidak dapat memisahkannya dengan nama Melaka. Hal ini dikatakan demikian kerana Hang Tuah ialah tokoh wira yang mengharumkan nama Melaka di segenap negara yang dilawatinya. Hang Tuah mempunyai lima orang sahabat, atau disebut sebagai "lima bersaudara", iaitu Hang Jebat, Hang Kasturi, Hang Lekir dan Hang Lekiu. Mereka berlima anak rakyat biasa yang menuntut ilmu 
pahlawan daripada seorang guru. Disebabkan ketangkasan dan keberanian mereka, maka mereka berjaya mengalahkan orang yang mengamuk di jalan ketika Bendahara melalui jalan tersebut. Bendahara Paduka Raja ialah orang yang bertanggungjawab membawa Hang Tuah lima bersaudara ke istana atas perintah sultan bagi membalas jasa mereka.

Bermula dari situlah, Hang Tuah dan sahabatnya menjalankan tugas hulubalang yang diberikan oleh baginda sultan. Hang Tuah merupakan hamba kesayangan sultan melebihi sahabat yang lain. Musuh utama Hang Tuah ialah Pateh Kerma Wijaya, iaitu orang yang bertanggungjawab memfitnah Hang Tuah sehingga menyebabkan wira ini dijatuhi hukuman mati oleh sultan. Akibat hukuman melulu oleh baginda sultan, Hang Jebat bangkit membela Hang Tuah dan merampas istana raja. Kisah ini begitu terkesan di hati masyarakat Melayu kerana pembelaan Hang Jebat itu, akhirnya dibalas dengan kematian di tangan sahabat yang dibelanya. Hukuman mati terhadap Hang Tuah rupa-rupanya tidak dilaksanakan oleh Bendahara seperti titah raja, sebaliknya Hang Tuah disembunyikan di Hulu Melaka. Apabila Hang Jebat menderhaka kepada Raja, Hang Tuah dititahkan untuk membunuh Hang Jebat. Kesetiaan kepada raja dan kesetiaan kepada sahabat ini menjadi isu yang amat menyentuh perasaan orang Melayu dan membuatkan kisah ini terus tersemat di hati masyarakatnya.

Kisah Hang Tuah mungkin bermula dalam bentuk lisan tersebar daripada satu generasi kepada satu generasi melalui pertuturan. Menurut Kassim Ahmad dalam tesisnya bertajuk "Characterisation in Hikayat Hang Tuah" (1959), teks hikayat ini dibukukan setelah lama dicipta sebagai sastera berbentuk lisan (Teuku Iskandar, 1995, hlm. 301). Hang Tuah telah diabadikan dalam dua buah karya yang dianggap agung dalam masyarakat Melayu hari ini. Karya tersebut dikenali sebagai Hikayat Hang Tuah dan Sulalat al-Salatin. Walaupun kedua-dua teks ini merakamkan Hang Tuah di dalamnya, tetapi kisah dan watak wira yang dipaparkan agak berbeza antara satu sama lain.

Semua perbezaan yang terdapat dalam dua teks ini pastinya mempunyai sebab-sebab tertentu. Kedua-dua teks tersebut daripada genre yang berlainan. Sulalat al-Salatin merupakan genre karya sastera bercorak sejarah, yang lebih dekat dengan perkara nyata. Sedangkan Hikayat Hang Tuah merupakan genre epik Melayu yang meriwayatkan cita-cita, kebaktian dan kebesaran bangsa Melayu melalui seorang wira, iaitu Hang Tuah. Hikayat ini meriwayatkan keseluruhan hidup Hang Tuah, bermula daripada pengisahan tentang keturunan raja yang Hang Tuah sembah, iaitu daripada keturunan dewa keinderaan bernama Sang Perta Dewa. Kemudian, teks ini mengkhususkan 
penceritaannya kepada asal usul Hang Tuah dan persahabatan, seterusnya menceritakan kisah kehidupannya sebagai diplomat, pahlawan terbilang, seorang yang bijaksana dan warak. Dalam semua ini, Hang Tuah ditampilkan sebagai manusia Melayu yang lengkap dengan sifat wira yang hebat berbeza daripada watak manusia biasa. Hang Tuah di Alam Melayu cukup terkenal bersama-sama empat sahabatnya, iaitu Hang Jebat, Hang Kasturi, Hang Lekir dan Hang Lekiu. Peristiwa pertikaman Tuah-Jebat ialah kisah yang tertanam dalam jiwa setiap manusia Melayu, dan kisah itu boleh dianggap sebagai satu pengajaran terhadap konsep "Setia dan Derhaka" bangsa Melayu. Hang Jebat menderhaka kerana marah kepada Raja yang menjatuhi Hang Tuah dengan hukuman mati tanpa usul periksa, manakala Hang Tuah menikam Hang Jebat kerana sahabatnya itu telah menderhaka kepada Raja Melaka. Konsep setia dan derhaka yang dijunjung oleh kedua-dua sahabat ini berbeza antara satu sama lain.

Lebih daripada itu, kisah ini sering dijadikan contoh dan dihidupkan kembali di pentas bangsawan untuk memperjelas peranan raja selaku pemerintah yang adil dan rakyat selaku hamba yang taat. Filem pertama yang menonjolkan Tuah-Jebat secara audio visual bertajuk Hang Tuah ditayangkan pada tahun 1956 di bawah arahan Phani Majumdar, kemudiannya diikuti oleh filem bertajuk Hang Jebat oleh Hussein Hanif pada tahun 1961. Biarpun kedua-dua filem ini antara adaptasi terawal yang menghidupkan watak Tuah-Jebat di layar perak, namun dikesani terdapat kecenderungan tertentu ketika pemfilemannya. Kedua-dua watak ini tampil dengan bacaan dan interpretasi yang berbeza oleh kedua-dua pengarah filem terdahulu. Filem Hang Tuah (1956) menghadirkan Hang Tuah sebagai wira yang berjaya membersihkan nama Raja Melaka dan menghapuskan Hang Jebat, manakala filem Hang Jebat (1961) menampilkan Hang Jebat sebagai wira dan penderhakaan yang dibuat semata-mata untuk membela sahabatnya yang dijatuhi hukuman mati kerana difitnah. Lebih tepat lagi, filem Hang Jebat ini bertujuan untuk memperkenalkan prinsip rakyat bawahan sekitar tahun lewat 1950-an, iaitu "raja adil raja disembah, raja zalim raja disanggah" yang tidak pernah tertulis dalam teks Hikayat Hang Tuah dan Sulalat al-Salatin, serta amat jauh bertentangan dengan waad yang dibuat oleh Demang Lebar Daun dan Seri Teri Buana.

Walau bagaimanapun, secara peribadi pengkaji mendapati kedua-dua filem ini sebenarnya mempunyai tujuan yang sama, iaitu mengangkat Hang Jebat sebagai tokoh yang patut dikenang sebagai wira dan bukannya sebagai penderhaka. Phani Majumdar juga telah menghadirkan satu persoalan pada 


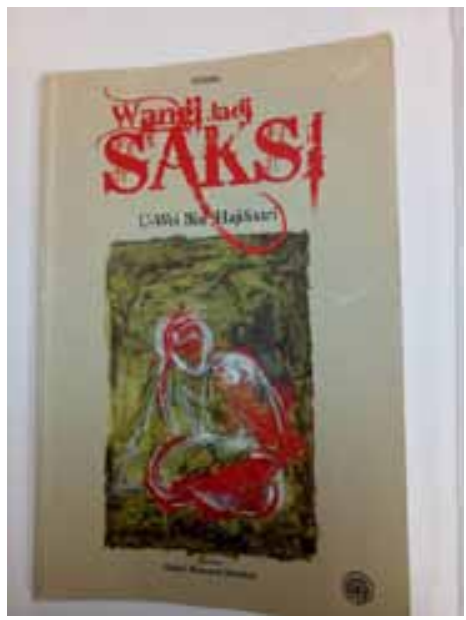

Rajah 1 Buku drama Wangi Jadi Saksi oleh U-Wei Haji Saari.

akhir filem tentang siapa yang sepatutnya diangkat menjadi wira, Tuah atau Jebat? Persoalan ini diajukan oleh watak Hang Tuah, dan tokoh ini dihadirkan sedang keliru dan menyesal dengan perbuatannya membunuh Hang Jebat. Jika diteliti dengan baik, kedua-dua filem ini cuba membersihkan nama Hang Jebat dan meletakkan kesalahan kepada Hang Tuah kerana tidak menghargai pengorbanan yang dilakukan oleh sahabatnya. Kisah pertikaman Tuah-Jebat ini dihidupkan semula ke drama pentas sekitar tahun 2006 melalui drama Wangi Jadi Saksi, arahan dan skrip oleh U-Wei Haji Saari.

\section{ADAPTASI DAN KONSEP}

Sebelum penelitian terhadap teks Wangi Jadi Saksi lebih mendalam, elok dijelaskan definisi dan pengertian adaptasi karya sastera ke bentuk seni yang lain khususnya filem dan drama. Menurut Hutcheon (2006, hlm. 20), adaptasi ialah suatu seni penyesuaian dan penyelamatan, serta merupakan proses interpretasi dan penciptaan yang baharu. Beliau berpendapat bahawa adaptasi ialah sebuah pengulangan tetapi "pengulangan tanpa peniruan" (2006, hlm.7). Usaha mengangkat karya sastera ke filem ini bukan semata-mata untuk memindahkan teks ke filem tetapi juga untuk menyesuaikan bentuk, cara kerja, naratif, plot dan elemen yang dianggap penting daripada bentuk kata-kata kepada bentuk visual. Semua usaha penyesuaian ini ditambahkan interpretasi yang telah dibuat secara selektif oleh pengarah dan orang-orang yang terlibat dalam pembuatannya. 
Adaptasi boleh berasal daripada novel, cerpen, drama, autobiografi, esei, novel grafik, puisi, lagu, kisah benar, sejarah, cerita lisan, dan sebagainya. Desmond dan Hawkes mengatakan bahawa adaptasi ialah suatu interpretasi yang melibatkan sekurang-kurangnya seorang pembaca teks yang memilih elemen tertentu yang ingin dipindahkan dan memutuskan cara untuk merealisasikan elemen tersebut dalam bentuk imej dan bunyi (2006:2). Usaha adaptasi walau bagaimanapun tidak boleh lari daripada dikaitkan dengan teks asal dan sering menjadi perhatian untuk dibandingkan bersama melalui persoalan kesetiaan. Hakikatnya pemindahan daripada satu medium kepada satu medium yang lain sentiasa membawa perubahan atau disebut juga sebagai reformatting (diulang format) dalam bahasa media baharu (Hutcheon, 2006, hlm.16).

Menurut Cardwell (2002, hlm. 13), adaptasi boleh dicapai dengan dua cara, iaitu pertama, setia kepada teks yang bermaksud setia dalam usaha menghasilkan semula elemen yang terdapat dalam buku ke skrin, dan menghantar kembali penonton kepada buku. Hal ini menjelaskan bahawa penonton yang juga merupakan pembaca secara tidak langsung mengingati elemen teks yang ditampilkan ke filem mahupun drama. Cara kedua, adaptasi merupakan olahan semula dan berjaya membuat penonton yang tidak membaca teks itu sebelumnya berasa terpanggil untuk membaca teks sesudah menonton filem. Usul ini menunjukkan bahawa usaha adaptasi sebenarnya satu usaha bersama yang saling mendukung. Teks yang dijadikan sumber merupakan penyumbang kepada tarikan penonton ke pawagam, manakala filem merupakan jambatan untuk khalayak lebih mengenali novel dan pengarangnya. Dalam erti kata lain, hubungan antara teks sastera dengan filem ini merupakan sebuah hubungan yang menguntungkan kedua-dua belah pihak.

\section{INTERTEKSTUALITI ADAPTASI}

Istilah intertekstualiti ini pertama kali diperkenalkan pada tahun 1966 oleh Julia Kristeva, sarjana lingustik Perancis melalui tulisannya yang bertajuk "Word, Dialogue and Novel". Beliau mengatakan teks terbentuk daripada mozaik-mozaik kutipan yang menyerap dan bertransformasi daripada satu teks kepada teks yang lain (1980, hlm. 66). Bell (1993), Barry (1995) dan Halliday (2002) berpendapat bahawa intertekstualiti merupakan sejarah teks dan rantai kitaran teks yang saling berhubungan, serta memiliki pengaruh terhadap teks baharu. Abrams (1982, hlm. 200) pula mengatakan bahawa intertekstualiti ialah cara kreatif untuk menandakan wujudnya gema teks 
dalam pelbagai cara melalui hubungannya dengan teks lain berdasarkan kutipan tertutup atau terbuka.

Kristeva pada mulanya terpengaruh dengan teori dialogisme Mikhail Bakhtin yang memberikan penilaian terhadap pelbagai makna atau disebut sebagai heteroglosia terhadap setiap teks dan kata. Menurut Bahktin, setiap teks memiliki dialog yang konsisten dengan teks lainnya. Dialog ini tidak bersifat satu hala tetapi merupakan interaksi dan reaksi terhadap teks sebelumnya yang dipengaruhi oleh teks baharu dan begitu juga sebaliknya. Dialogik Bakhtin percaya bahawa teks terbentuk hasil hubungan antara teks dalaman dengan teks luaran (Bakhtin, 1986, hlm. 104-105). Teks dalaman ialah aspek yang berkaitan dengan pembinaan teks seperti estetika, imaginasi dan ilusi, manakala teks luaran ialah perkara sosial yang menyangkut pengalaman, ideologi, sejarah, moral dan budaya pengarang. Oleh hal yang demikian, menurut Bakhtin teks tidak dapat dipisahkan daripada teks luaran atau teks sosial yang mempengaruhi pengarang untuk menghasilkan teks tersebut.

Lanjutan itu, Kristeva (1980) mengatakan teks tidak berdiri sendiri sebagai objek terasing, tetapi terbentuk daripada hubungannya dengan teks lain. Hal ini mengakibatkan teks tidak mempersembahkan makna yang stabil dan jelas kerana makna tersebut mengandungi kombinasi dan kompilasi bahagian teks sosial yang mempunyai pengaruh terhadapnya. Sebagai tambahan Kristeva menyatakan bahawa makna tidak pernah berpindah secara langsung daripada pengarang kepada pembaca, tetapi telah melalui kod-kod yang diambil dan diubah suai oleh pembaca dan pengarang sebagai hasil daripada teks lain yang telah mempengaruhi mereka (Allen, 2000, hlm. 37). Dengan kata lain, setiap teks merupakan kumpulan rujukan kepada teks lain sehingga dengan ketiadaannya teks tersebut tidak dapat wujud. Semua penerangan di atas hanya sebagai pengulangan daripada fahaman dialogisme Bahktin yang memantapkan hubungan antara pengarang, karya, pembaca, masyarakat dengan sejarah.

Dalam konsep intertekstualiti, teks yang menjadi sumber penciptaan teks baharu disebut sebagai hipogram (Riffatera, 1978, hlm. 23), manakala teks baharu yang terhasil daripada hipogram disebut sebagai karya transformasi. Hubungan antara teks terdahulu dengan teks baharu disebut sebagai hubungan intertekstualiti. Unsur yang diserap oleh karya transformasi boleh sahaja bersifat kata demi kata, ayat, model bentuk, dan idea yang membentuk karya baharu berbeza sehingga membuatkan hipogramnya tidak lagi dikenali (1978, hlm. 165). Barthes melalui eseinya "The Death of the Author" menyatakan bahawa kesatuan teks tidak berada pada sumber asal, tetapi berada pada 
destinasi atau makna yang diberikan oleh pembaca. Makna yang ditanggapi pembaca akan mengakibatkan kematian pengarang, iaitu bukan dalam makna sebenar kematian pengarang kerana pengarang juga tidak pernah benar-benar hidup (Barthes, 1981, hlm. 142-148). Masyarakat, pembaca dan penonton yang mengubah pandangan mereka terhadap individualiti pengarang dan meletakkan identiti kepadanya sehingga reaksi pembaca menjadi penting untuk memberikan makna kepada gambaran yang terdapat dalam teks tersebut. Oleh hal yang demikian pemahaman teks menjadi luas kerana pembaca tidak mengambil secara utuh keinginan si pengarang, tetapi memberikan tafsiran sendiri yang secara tidak langsung memperkaya makna teks tersebut.

Dalam konteks filem adaptasi, pandangan Barthes sebelumnya tentang makna yang diberikan pembaca atau masyarakat terhadap teks boleh juga digunakan untuk mengkaji atau menganalisis filem adaptasi yang menjadikan teks sebagai sumber, dan memberikan jawapan kepada persoalan yang sentiasa menyelubungi usaha adaptasi. Ketika meneliti hubungan antara novel dengan filem kebanyakan daripada penilaian itu mengarah kepada harapan agar hasil adaptasi menjadi seperti malah sehebat karya yang dijadikan sumbernya. Penilaian seperti ini membangkitkan isu kesetiaan yang secara tidak langsung mengaitkan filem adaptasi sebagai sebuah karya intertekstualiti kerana teks bertulis (novel atau hikayat) ditransformasikan dalam teks visual (filem). Jika dilihat daripada penjelasan Riffatere, karya sastera ialah hipogram dan filem adaptasi ialah karya transformasi. Jika dilihat pula penjelasan mengenai intertekstualiti itu sendiri, filem adaptasi ialah karya yang terpengaruh dengan karya sastera, dan merupakan sebuah interpretasi subjektif seseorang pengarah terhadap karya tersebut.

Sinyard (1996, hlm. 117) berpendapat bahawa adaptasi karya sastera dalam filem cenderung memberikan perhatian kepada interpretasi pengarah terhadap teks sastera yang menjadi sumber, dan disesuaikan dengan pendekatan mereka sendiri. Dalam konteks ini, interpretasi dianggap sebagai kritis dan bukan hanya bertujuan untuk menghasilkan semula teks itu dalam bentuk drama pentas, tetapi lebih kepada membentuk cahaya baharu terhadap sumber asli (1996, hlm. 117). Analisis terhadap drama adaptasi merupakan satu cara untuk menonjolkan elemen intertekstualiti teks yang terbenam dalam karya drama dan melihat cara teks sumber menguasai atau menyumbang kepada penghasilan karya baru. Semakin banyak elemen intertekstualiti dalam sesebuah karya adaptasi maka semakin akrab hubungan drama tersebut dengan teks asalnya, dan begitu juga sebaliknya. 
Pemahaman terhadap teks dinilai melalui proses pembacaan yang berbeza melibatkan seorang pengarah atau penulis skrip dengan seorang pembaca biasa. Iser mengatakan proses pembacaan melibatkan interaksi antara teks dengan pembacanya (1987, hlm. 20). Setiap pembaca karya sastera akan berdialog dengan teks atau novel yang dibaca dan disesuaikan dengan imej mental yang dibentuk oleh imaginasi mereka. Pembentukan setiap imej mental antara pembaca A dengan pembaca B berbeza kerana mereka dipengaruhi oleh latar pengalaman seperti pendidikan, agama, masyarakat, budaya, dan sebagainya yang juga turut berbeza. Hal ini dijelaskan oleh Iser (1978, hlm. 11) seperti dalam petikan yang berikut:

... throughout the reading process there is a continual interplay between modified expectations and transformed memories. However, the text itself does not formulate expectations or their modification; nor does it specify how the connectability of memories is to be implemented. This is the province of the reader himself, and so here we have the first insight into how the synthesizing activity of the reader enables the text to be translated and transferred to his own mind.

Petikan ini menjelaskan hubungan saling mempengaruhi antara memori dengan harapan ketika proses pembacaan berlaku. Memori dan harapan tidak pernah dibentuk oleh teks tersebut, dan hal ini hanya dibentuk oleh pembaca berdasarkan sistem tanda atau lambang yang dihadirkan oleh pengarang. Pembaca menginterpretasikan penanda atau lambang yang dihadirkan pengarang berdasarkan pengalaman, ingatan, dan ideologi seseorang pembaca itu. Proses ini menjadi asas kepada setiap pembaca dalam usaha menginterpretasikan teks yang dibaca termasuk para pembuat filem. Pengarah dan penulis skrip misalnya mengambil idea yang terdapat dalam teks berdasarkan interpretasi mereka terhadap teks tersebut, dan ditampilkan dalam bentuk imej visual dalam filem (bagi konteks drama pentas, interpretasi itu ditampilkan melalui dialog, prop, muzik, nyanyian, pencahayaan, solekan dan lakonan). Sama halnya dengan situasi pembaca yang menikmati teks sastera dengan membentuk dan membayangkan imej dalam minda mereka ketika proses pembacaan sedang berlangsung. Apabila teks itu dipindahkan kepada bentuk yang lain seperti drama, pembaca menikmati cerita tersebut melalui lakonan, dialog, pencahayaan dan pertukaran prop yang disampaikan secara langsung di hadapan penonton. Imaginasi yang dibentuk ketika proses pembacaan tidak lagi menyamai gambaran realiti yang hadir di atas pentas. 


\section{ANALISIS DRAMA WANGI JADI SAKSI}

Seperti yang telah dijelaskan sebelumnya, adaptasi merupakan sebuah tafsiran semula terhadap teks dan membawa ideologi baharu (Stam, 2000, hlm. 61). Pernyataan ini telah dijelaskan oleh Ingham (1998, hlm. 430) dengan mengatakan adaptasi "memunculkan makna yang lebih segar", dan memberikan tenaga baharu kepada teks lama dengan menawarkan naratif dalam ruang realiti, dan melebarkan skop penceritaan tertentu dalam teater. Ingham yakin bahawa penyesuaian boleh dilakukan terhadap teks yang ingin diadaptasikan kepada teater seperti yang berikut:

People enjoy novels because they tell stories, and these stories ... can come vibrantly to life again in a multi-levelled totally theatrical experience combining physicality and presence with narrative, music and spatio-temporal freedom in order to stimulate the mind and senses.

(Ingham, 1998, hlm. 438)

Dengan kata lain, adaptasi merupakan usaha mencukupkan makna daripada karya asal. Memadankan dan mencukupkan makna merujuk keinginan untuk menggantikan satu ilusi sebenar dengan yang lain. Keadaan ini boleh dikaitkan dengan usaha pengarah filem tempatan yang terkenal, iaitu U-Wei Haji Saari menerusi teater arahannya bertajuk Wangi Jadi Saksi. U-Wei menampilkan semula kisah pertikaman Hang Tuah dan Hang Jebat dalam versi yang berlainan daripada sejarah yang terakam dalam teks Hikayat Hang Tuah dan Sulalat al-Salatin. Teater ini mengupas kisah di sebalik sejarah tersebut dengan menghadirkan watak "Wangi" sebagai isteri Hang Jebat. Wangi digambarkan menjadi saksi mata dan penyimpan rahsia kepada peristiwa besar pertikaman dua sahabat tersebut. Watak "Wangi" ialah interpretasi U-Wei daripada cerita yang tidak pernah dikisahkan pada zaman pemerintahan Kesultanan Melayu Melaka yang ketika itu berada di bawah naungan Sultan Mansur Syah (Azman Ahmad, 2006). "Wangi" menjadi saksi terhadap kematian Hang Jebat yang mati bukannya di tangan Hang Tuah tetapi di tangan Pateh Kerma Wijaya.

Teater ini bukan lagi mengisahkan pertelingkahan Hang Tuah dan Hang Jebat, tetapi menjadi gelanggang perdebatan antara Wangi dengan Pateh Kerma Wijaya. Kisah pertikaman ini dirungkai semula dan diberikan tafsiran yang berbeza daripada sejarah yang sedia ada. Dalam usaha memberikan tafsiran baharu, U-Wei dilihat telah mencipta satu teks baharu. Beliau telah meruntuhkan kenyataan yang sudah diterima masyarakat berabad-abad 


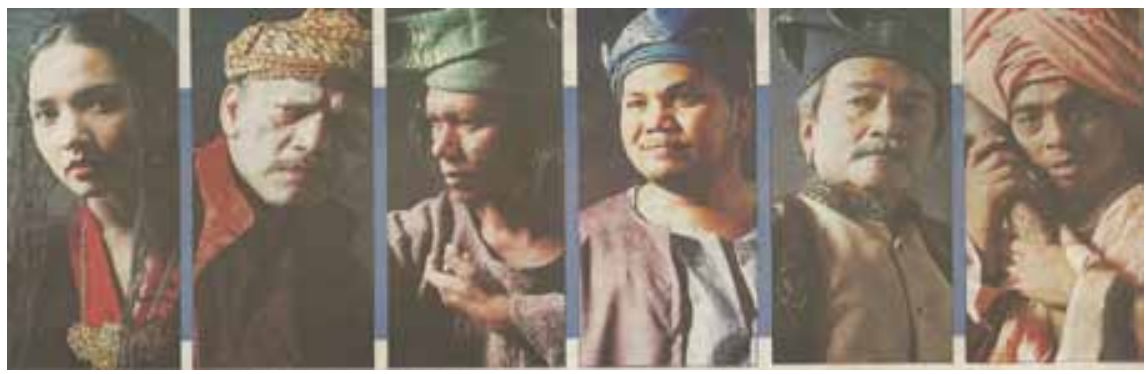

Rajah 2 Barisan pelakon Wangi Jadi Saksi (dari kiri) Vanidah Imran, Khalid Salleh, Khir Rahman, Sobri Anuar, Rahim Razali dan Sabri Yunus.

(Sumber: Pancaindera, Ahad, 30 Julai 2006)

lamanya tentang kisah pertikaman Tuah-Jebat dengan melontarkan satu kemungkinan baharu. Sehubungan dengan itu, U-Wei menjelaskan bahawa beliau yakin "sejarah pada lapis apa sekalipun masih merupakan spekulasi" (Noor Azam, 2006, hlm. 14). Sifat sejarah itu sendiri adalah subjektif dan sarat dengan mitos serta legenda yang sering menimbulkan pelbagai persoalan. Oleh itu, adalah wajar jika sejarah itu sering ditafsirkan secara berbeza-beza oleh golongan pembaca yang berbeza zaman, ideologi, pendidikan dan sebagainya, seperti yang ditegaskan oleh U-Wei Haji Saari (Noor Azam, Julai 2006, hlm. 14):

Sejarah itu tidak pernah mati. Ia mesti kita baca dan tafsir lagi, baca dan tafsir lagi. Kita jangan lupa itu.

Bersandarkan penjelasan di atas, pengkaji mendapati teater ini mengubah peranan sudut pandangan orang ketiga serba tahu dalam teks Hikayat Hang Tuah dan Sulalatus al-Salatin. Suasana pertikaman itu dihadirkan dalam teater dari pelbagai sudut sehingga gerak dan langkah silat setiap tokoh diperihalkan secara terperinci bertujuan untuk menjawab setiap persoalan yang muncul daripada kisah pertikaman tersebut. Suasana amarah dan pergelutan TuahJebat dalam teks klasik ditukar menjadi suasana damai yang menyenangkan melalui gambaran pertemuan dua sahabat karib yang melepaskan rindu dan mengenang nasib diri. Jebat digambarkan akur dan sanggup mati di tangan Hang Tuah, manakala Hang Tuah pula ditekan rasa bersalah antara taat kepada sultan atau kasih pada sahabat. Akhirnya, pertemuan itu diakhiri dengan Hang Tuah pergi meninggalkan Hang Jebat sendirian di balik tirai tanpa menikam dan membunuh Hang Jebat seperti yang berikut: 
HANG JEBAT

Kalau kau tak sanggup menikamku, biar aku menunggu di sebalik tirai. Tak payah kita bertentang mata, tak payah kau lihat air mataku. Air mata yang mengalir ini jangan disangka kesedihan tetapi lihat ia sebagai keredaan. Abang Tuah abangku yang setia. Pengorbananmu tidak ada batasnya. Aku rela untuk menjaga nama.

(HANG JEBAT berdiri di depan tabir menunggu tikaman HANG TUAH)

(U-Wei Haji Saari, 2010, hlm. 68)

\section{HANG TUAH}

Jebat adikku yang satu. Banyak perkara, banyak peristiwa, banyak waktu kita bersama. Banyak kala tiada kau di situ, tiadalah aku ada juga. Banyak mana kita berdua dapat bongkarkan, banyak lagilah yang tak dapat kita capai, tetapi semuanya itu aku faham sefaham aku daripada bahasa perutku sendiri.

(U-Wei Haji Saari, 2010, hlm. 74)

\section{HANG JEBAT}

Telah aku lakukan apa aku lakukan, dan sekarang abangku, aku bersedia, kauselesaikanlah tugasmu pula. Aku tidak tahan menunggu lagi.

(U-Wei Haji Saari, 2010, hlm. 76)

HANG TUAH

Dan membunuh kau Jebat adikku, bukannya aku.

(HANG TUAH pergi. Kedengaran dengungan wirid HANG JEBAT yang menunggu).

(PATEH KERMA WIJAYA melihat HANG TUAH tidak melakukan kerja penghujung itu. HANG TUAH berselisih dengan PATEH KERMA WIJAYA tetapi terus pergi).

(U-Wei Haji Saari, 2010, hlm. 77-78)

U-Wei menulis dan mengarahkan teater ini untuk memberikan keadilan yang setimpal kepada kedua-dua tokoh, iaitu Hang Tuah dan Hang Jebat tanpa bertujuan untuk menyalahkan salah seorang antara mereka. U-Wei seolah-olah nampak siapa petualang sebenar dalam kisah Hang Tuah, dan berniat menghukum Pateh Kerma Wijaya yang dibiarkan bebas tanpa 
balasan dalam Hikayat Hang Tuah dan Sulalat al-Salatin walaupun telah beberapa kali berusaha memfitnah Hang Tuah. Melalui drama ini, U-Wei menghadirkan watak Dang Wangi sebagai watak ketiga yang ada dalam peristiwa pertikaman Tuah-Jebat di istana raja. Beliau diminta Jebat untuk menyediakan hidangan ketika pertemuan dua sahabat itu di dalam istana. Watak keempat ialah Pateh Kerma Wijaya yang masuk ke ruang istana setelah tidak sabar untuk melihat Jebat dibunuh.

Akibat marah akan sikap Hang Tuah yang pergi meninggalkan Hang Jebat tanpa menyelesaikan tugasnya, Pateh mengambil keris yang ditinggalkan dan menikam Hang Jebat yang masih berada di balik tirai dan tidak menyedari pemergian Hang Tuah (U- Wei Saari, 2010, hlm. 78-79). Marah dengan tindakan Pateh, Hang Jebat keluar mengamuk dan membunuh rakyat lain di luar istana. Kematian Hang Jebat ditikam Hang Tuah tersebar seantero negeri. Rakyat yang menyebelahi Hang Jebat menyimpan rasa tidak senang pada Hang Tuah, manakala rakyat yang menyebelahi Hang Tuah menyimpan rasa benci pada Hang Jebat. Pertikaman itu memberikan kesan buruk kepada peribadi kedua-dua tokoh dan nilai persahabatan mereka. U-Wei mengesan ketidakadilan yang wujud dalam kedua-dua teks klasik ini. Beliau berusaha menggambarkan keadaan "pelaku sebenar" yang masih terlepas daripada tuduhan dan bebas melaksanakan tugas harian sebagai pembesar istana. Dang Wangi dimunculkan untuk menuntut bela atas kematian Hang Jebat dan berusaha membersihkan nama Hang Tuah sebagai sahabat yang harus dicontohi.

Jika diteliti kedua-dua teks klasik tersebut, suasana pertikaman antara Hang Tuah dengan Hang Jebat ini disampaikan oleh pengarang yang menjadikan diri mereka sebagai orang ketiga serba tahu dan rakyat Melaka yakin bahawa Hang Tuah dan Hang Jebat sedang bertikam berdasarkan bunyi di atas dulang. Pada ketika itu, seluruh rakyat sedang berada di bawah istana untuk mendengar dan membantu Hang Tuah membunuh Hang Jebat dengan menghunus senjata dari bawah istana. Suasana ini dikekalkan dalam Wangi Jadi Saksi, dan berfungsi untuk mengingatkan khalayak bahawa rakyat yang berada di luar istana itu sebenarnya tidak tahu keadaan sebenar yang sedang berlaku di dalam istana. Peranan pengarang sebagai orang ketiga serba tahu telah diambil alih oleh U-Wei, dan beliau kini menghadirkan satu kemungkinan baharu, iaitu bunyi dulang dari istana itu adalah kerana Hang Tuah dan Hang Jebat cuba menyelamatkan diri mereka daripada menjadi mangsa tusukan rakyat yang mahu Hang Jebat dibunuh dengan segera. Hal ini dapat dilihat dalam dialog yang berikut: 
HANG JEBAT

Celaka mereka! Akan aku amuk hingga ke bawah! Tidak lain kalau tak menikam curi. Dasar pengecut satu Melaka.

(SUARA rakyat Melaka di bawah yang mencucuk lembing dari bawah rumah)

HANG TUAH

Mereka fikirkan untuk melihat kita bagai menyaksikan temasya.

(HANG JEBAT menutup tingkap)

HANG JEBAT

Dan itu kita berikan dulu.

(HANG JEBAT mengambil dulang yang ada di situ)

HANG JEBAT

Wangi, bawa semua dulang ke mari!

(Dicampaknya semua dulang di lantai. Dan berlaga berbunyi kuatlah dulangdulang di dalam istana). (Muzik muncul; seoalah-olah muzik pencak silat pertarungan). (Kedengaran sorakan ramai di luar. Muzik bertambah rancak).

(U-Wei Haji Saari, 2010, hlm. 47-49)

Situasi dalam dialog di atas menghadirkan kemungkinan bahawa Hang Tuah dan Hang Jebat sedang mewujudkan helah seolah-olah mereka sedang bertarung sesama sendiri, walhal kedua-dua pahlawan ini sedang berbincang tentang nasib yang menimpa mereka.

U-Wei mengakui beliau menulis Wangi Jadi Saksi bersandarkan pelbagai persoalan antaranya, "Bagaimana lagaknya dua beradik yang lama terpisah kerana disangkakan mati apabila berjumpa kembali? Apabila bertemu, apakah yang mereka bualkan? Apakah benar mereka bertarung tanpa henti selama berhari-hari? Kenapa Jebat mengamuk? Apakah dia mengamuk sebelum bertikam dengan Tuah, atau selepas cedera parah ditikam? Apakah yang barangkali berlaku, selain daripada apa yang dihikayatkan dalam teks lama Melayu itu?" (Noor Azam, 2006, hlm. 14-15). Bagi U-Wei, kisah Hang Tuah ialah sebuah sejarah yang sarat dengan mitos dan legenda, maka kisah tersebut tidaklah bersifat sejarah secara faktual dan lebih cenderung tergolong dalam kelompok sastera tradisi. Bacaan U-Wei didorong oleh interpretasinya sebagai 
pembaca yang cuba mempersoalkan tradisi dan mengajukan kemungkinan yang boleh berlaku dalam peristiwa pertikaman tersebut.

Walau bagaimanapun, U-Wei tidaklah bertegas untuk menjatuhkan hukuman drastik kepada Pateh Kerma Wijaya, dan beliau tidak berusaha untuk mengubah kisah pertikaman Tuah-Jebat. Wangi tidak ditampilkan sebagai wanita yang berjaya membunuh atau mencederakan Pateh Kerma Wijaya, malah suara Wangi juga tidak didengar oleh raja dan pembesar Melaka yang lain. Kesaksian Dang Wangi hanya diutarakan pada Pateh Kerma Wijaya dan kesaksian itu berjaya dipatahkan oleh watak antagonis ini seperti yang berikut:

\section{DANG WANGI}

Kanda Jebat tahu pasti, yang menikam bukan yang disetujui, yang diterima bukan yang dia sudi. Pateh Kerma Wijaya batang hidung yang dicari. Di mana kau Pateh pergi sembunyi? Habis rakyat menghalang di luar istana diamuk Kanda Jebat mati. Langsung abangnya Tuah tidak lagi mahu campur tangan. Darah Melaka sekali lagi menjadi bayaran. Kanda Jebat mengamuk hanya dibiarkan. Mereka tahu. Apa bukan begitu? Apa bukan begitu Pateh? Apakah bukan ...?

\section{PATEH KERMA WIJAYA}

Membunuh kau tidak ada gunanya. Apa yang tahu, rumusan yang ingin kau sebar tak akan ke mana. Tengok kau ini Wangi membuat kerja yang tak terdaya. Satu kejadian yang hiba. Segalanya telah terlanjur. Jagalah anak kau yang diamanahkan. Syukurlah kerana tidak kami hapuskan zuriat Jebat yang ada. Ingat itu! Kau masih dikasihani, Wangi.

\section{DANG WANGI}

Itu yang lagi kejam.

(DANG WANGI amat pilu hatinya. Dia duduk terkulai bersimpuh semula di lantai).

(U-Wei Haji Saari, 2010, hlm. 86-87)

Dengan itu, kematian Jebat kekal sebagai tindakan yang dilakukan oleh Hang Tuah, dan Hang Jebat tetap dianggap berdosa kerana menderhaka. Walaupun secara tersurat suara Wangi tidak diendahkan Pateh Kerma Wijaya 
dan tidak mampu mengubah peristiwa yang telah berlaku, namun Wangi tetap melontarkan kenyataannya kepada khalayak penonton seperti yang berikut:

\section{DANG WANGI}

Jika datangnya semua mengumpul bahan, meletak beban, penuh kesengsaraan, - ke atas badan ini, sini aku katakan, perkelahiannya kau orang yang mulakan - akunya punca tindakan Pateh. Pateh pula tindakan daripada Bendahara, Bendahara daripada menteri-menteri raja dan gundiknya dan ..., dan siapa, pada siapa yang bermula dan berhentinya? Sudah tentu tiada yang tidak bersalah. Pergaduhan menyedut hidup sepanjang hayat. Aku ini Dang Wangi isteri Hang Jebat, janganlah lupa alahai anak-anak; melihat meragut kedudukan mengosongkan takhta; Abang Jebatku raja akulah permaisuri istana, jangan kaulupakan ...

Dialog ini ialah penyataan terbuka Wangi tentang semua hal yang berlaku di sebalik kisah pertikaman Tuah-Jebat dan dalang yang menjadi punca kepada runtuhnya semangat setia kawan ini. Dalam naskhah ini, Wangi diberikan tanggungjawab yang cukup besar oleh U-Wei untuk menegakkan kebenaran dan membersihkan nama, serta maruah dua tokoh penting dalam

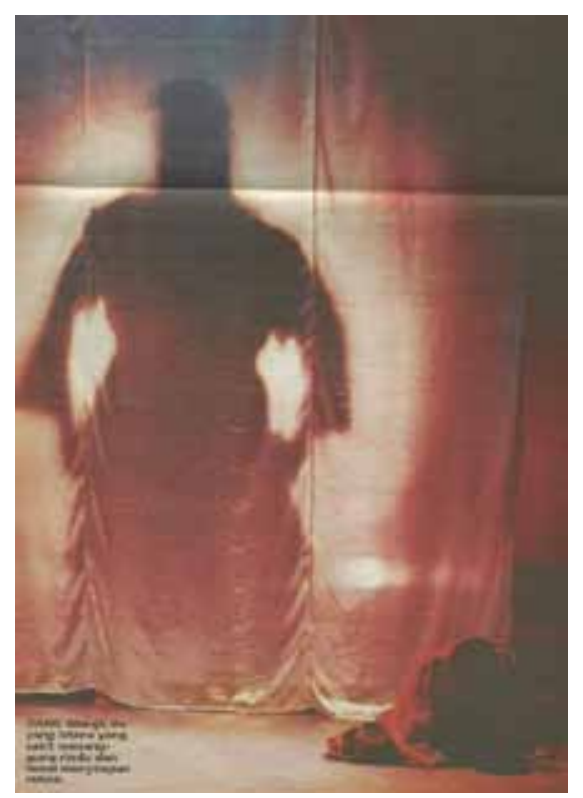

Rajah 3 Dang Wangi duduk bersimpuh dilantai meratapi kematian Hang Jebat. (Sumber: Pancaindera, Ahad, 30 Julai 2006) 
legenda Melayu. Wanita ini perlu menghadapi Pateh Kerma Wijaya yang terkenal dengan tipu muslihat, malah mampu memperdayakan sultan Melaka. Meskipun begitu, Wangi pada akhirnya berjaya membuktikan bahawa Pateh Kerma Wijaya ialah punca kepada tersebarnya fitnah bahawa Hang Tuah telah membunuh Hang Jebat kepada khalayak penonton. Drama ini ditamatkan dengan paparan Kota Melaka di layar pentas sebagai menggambarkan bahawa kisah tragis pertikaman dua sahabat itu menjadi legenda dan merupakan sebahagian daripada kisah terkenal Kota Melaka.

Perdebatan antara Wangi dengan Pateh Kerma Wijaya sebenarnya satu usaha untuk mengajak khalayak pembaca dan penonton untuk sama-sama berfikir tentang kemungkinan yang boleh berlaku dalam kisah tersebut. Pateh Kerma Wijaya tetap dibiarkan bebas dalam drama ini dengan tujuan mengganggu perasaan khalayak pembaca dan penonton. U-Wei berniat untuk mengingatkan penonton tentang seorang tokoh antagonis dalam teks klasik yang selalu menyimpan dendam dan berniat jahat terhadap Hang Tuah tetapi tidak pernah diberikan hukuman yang setimpal pada masa silam.

Wangi Jadi Saksi ialah sebuah drama yang hanya menampilkan enam watak, iaitu Bendahara, Pateh Kerma Wijaya, Hang Tuah, Hang Jebat, Dang Wangi dan Masa. Masa berfungsi sebagai pencerita. Watak ini menegaskan bahawa dirinya tidak mempunyai kepentingan dan pengaruh, tetapi sebenarnya watak ini menyimpan dan menjadi saksi kepada pelbagai kisah yang berlaku di dunia. Kehadiran watak Masa adalah untuk menghadirkan semula kisah silam zaman Melaka dan kisah pertikaman Tuah-Jebat yang tidak mendapat pembelaan sesiapa biarpun muncul saksi mata seperti Dang Wangi dalam kisah tersebut. Masyarakat percaya kepada kisah yang didengar dan diceritakan sahaja, malah mereka tidak menerima kisah yang tidak tercatat dalam teks dan sejarah seperti yang diperihalkan oleh Wangi dan disaksikan oleh Masa.

Interpretasi U-Wei ini dilihat sebagai wajar kerana pengkaji mengesan beberapa perkara yang memungkinkan kisah ini ditulis semula. Menerusi kisah pertikaman tersebut, pembaca membayangkan situasi pertikaman itu bermula daripada halaman 381 hingga 392 dalam Hikayat Hang Tuah. Sepanjang pergelutan, Hang Tuah menegaskan bahawa tindakannya membunuh Hang Jebat kerana menjunjung titah raja. Dari satu sisi, sebagai pembaca kita telah diingatkan dari awal hikayat bahawa teks ini ditulis untuk menggambarkan kesetiaan seorang hamba yang patuh dan taat kepada rajanya. Walau bagaimanapun, terdapat persoalan yang timbul ketika Hang Tuah meninggalkan Hang Jebat yang luka terkena tikaman tanpa menamatkan riwayat sahabatnya itu. Hang Tuah digambarkan dalam teks pulang ke 
rumah berkhalwat selama tiga hari, dan tokoh ini mengetahui perihal Hang Jebat mengamuk dan membunuh orang-orang Melaka, seolah-olah merelakan apa-apa yang dilakukan oleh sahabatnya itu (Kassim Ahmad, 1997: 366-367). Kasih sayang Hang Tuah kepada sahabatnya juga dapat dilihat setelah membunuh Hang Jebat, Hang Tuah sempat menyuapkan sekapur sirih kepada Jebat sebelum beliau menghembuskan nafasnya yang terakhir di atas riba Hang Tuah (Kassim Ahmad, 1997, hlm. 368). Namun, apa yang lebih penting ialah pesanan Hang Jebat kepada Hang Tuah tentang anaknya yang dikandung Dang Baru, iaitu dayang Datuk Bendahara. Walaupun raja Melaka menitahkan Hang Kadim, iaitu anak Hang Jebat agar dibuangkan ke laut, tetapi Hang Tuah tidak menjalankan perintah tersebut. Sebaliknya, beliau memohon kurnia atas nama Tun Teja agar dapat menghantar Hang Kadim kepada Bendahara Seri Buana di Inderapura (Kassim Ahmad, 1997, hlm. 370). Hal ini mungkin kerana kekangannya sebagai seorang Laksamana yang tidak membolehkannya memelihara anak seorang penderhaka, tetapi beliau tetap melakukan yang terbaik buat anak sahabatnya itu.

Melalui semua persoalan dan persahabatan yang ditampilkan dalam teks klasik ini, maka tidak hairanlah jika U-Wei menampilkan satu tafsiran baharu terhadap kisah tersebut. Di satu sisi, kita sedar bahawa Hang Tuah juga tidak patuh sepenuhnya kepada perintah raja dalam hal melibatkan sahabatnya Hang Jebat. Walau bagaimanapun, isu tidak setia Hang Tuah ini didiamkan oleh keseluruhan pembacanya, seolah-olah hal mendapatkan kehidupan kepada Hang Kadim itu bukan hal yang dianggap derhaka. Kasih sayang Hang Tuah diangkat oleh U-Wei dengan mengajak penonton bersama-sama meletakkan kesalahan itu kepada Pateh Kerma Wijaya kerana tokoh ini telah dua kali memfitnah Hang Tuah dengan fitnah yang sama, iaitu menginginkan dayang istana.

Naskhah drama Wangi Jadi Saksi menjadi medan perdebatan Wangi membongkar tipu muslihat dan dendam Pateh Kerma Wijaya yang disebut sebagai lahap dan tamak haloba (U-Wei Haji Saari, 2010, hlm. 55). Melalui watak Wangi, khalayak penonton diberitahu bahawa Hang Tuah ialah penghalang kepada hasrat pembesar-pembesar negeri mengaut untung daripada kutipan cukai yang dikenakan kepada pedagang dari luar negara. Maka, Pateh Kerma Wijaya mengetuai rancangan untuk menghapuskan Hang Tuah bermula daripada kisah kuda kesayangan sultan yang jatuh ke lubang najis (U-Wei Haji Saari, 2010, hlm. 54). Akan tetapi, semua rancangan tersebut gagal, sehinggalah akhirnya Hang Jebat dijadikan sebagai mangsa kepada dendam tersebut. Semua perhatian dan kesalahan diletakkan pada 
bahu Hang Jebat apabila tokoh ini menderhaka kepada raja kerana membela sahabatnya sehinggakan semua kesalahan pembesar yang lain tidak lagi diberikan perhatian serius.

Sesuatu yang lebih menarik ialah U-Wei juga telah menghadirkan satu tafsiran yang diluar jangkaan tentang Bendahara Melaka. Perhatikan dialog yang berikut untuk mengesan muslihat yang terselit disebaliknya:

\section{BENDAHARA}

Tiada apa berita didengar, jadi pasti dia ibaratkan orang menunggu sahaja. Diam di Hulu Melaka setahu semua yang ikut menghantar. Seorang pendekar menerima perintah, tidak keberatan keseorangan, diletak di hutan belantara mana sekalipun, dirinya dapat dihiburkan.

\section{PATEH KERMA WIJAYA}

Elok bersua awalnya, jangan kita yang dulu dan lakukan.

\section{BENDAHARA}

Tidak ramai yang tahu. Jangan pula terheret nama orang baik-baik Melaka.

\section{PATEH KERMA WIJAYA}

Kerja hamba juga menjaga nama baik kita semua, Orang Kaya. Kita hantar penghulu bendahari untuk bersua muka memberi berita dan perintah yang baru pula kita ajukan nanti di istana.

(BENDAHARA mengangguk perlahan sebagai bersetuju).

\section{PATEH KERMA WIJAYA}

Tuah yang empunya permulaan dan Si Tuah juga yang akan menyudahkan.

(U-Wei Haji Saari, 2010, hlm. 10)

Persembunyian Hang Tuah oleh Bendahara bukan lagi rahsia seperti kisah yang tercatat dalam teks Hikayat Hang Tuah dan Sulalat al-Salatin, persembunyian Hang Tuah di tangan U-Wei merupakan muslihat terancang oleh Bendahara dan Pateh Kerma Wijaya bersama-sama pembesar Melaka yang tidak puas hati dengan perhatian yang diberikan sultan kepada Hang Tuah. Kepercayaan sultan kepada Hang Tuah membuatkan semua rancangan mengaut keuntungan daripada pedagang asing gagal dan kerana itulah muslihat demi muslihat diatur untuk menjatuhkan Hang Tuah dan menamatkan riwayat Hang Jebat, sahabat yang dilihat mampu merosakkan semua rancangan jahat pembesar Melaka. 


\section{KESIMPULAN}

U-Wei memilih satu kisah besar daripada teks klasik Hikayat Hang Tuah dan Sulalat al-Salatin yang kedua-duanya mencatatkan kisah pertikaman dua sahabat ini. Beliau bukan sahaja melakukan apa-apa yang disarankan Stam tentang sebuah teks mampu berkembang dan melahirkan teks lain, malah mengajak pembaca dan penonton dramanya untuk sama-sama berfikir tentang ketidakadilan yang berlaku pada zaman silam. Hang Tuah difitnah oleh Pateh Kerma Wijaya sebanyak dua kali, dan Hang Jebat menderhaka kerana marah terhadap tindakan raja yang menjatuhkan hukuman kepada Hang Tuah tanpa usul periksa. Semua keadaan ini berlaku disebabkan Pateh Kerma Wijaya, tetapi watak ini dibiarkan bebas tanpa hukuman. Dalam usaha untuk menghukum Pateh Kerma Wijaya, U-Wei menghadirkan teks baharu bertajuk Wangi Jadi Saksi berdasarkan persoalan yang muncul dalam kisah yang tercatat dalam kedua-dua buah teks klasik Melayu. Watak Wangi diwujudkan untuk memberikan jawapan dan kemungkinan terhadap sejarah setia kawan Tuah-Jebat menerusi interpretasi semula U-Wei Haji Saari. Intinya, drama ini ialah mangkin atau pentas untuk khalayak mempersoalkan masa silam, dan U-Wei memilih kisah pertikaman TuahJebat sebagai pencetus kepada tujuan itu.

\section{RUJUKAN}

Abrams, M., H. (1982). Glossary of literary terms. Holt, Rinehart and Winston: New York.

Allen, Graham. (2000). Intertextuality. Routledge: London.

Azman Ahmad. (2006). Play will prove Malay history is very much alive. New Straits Times, 1 Julai 2006, halaman 6-9.

Bakhtin, Mikail. (1986). Speech genres and other late essays. Caryl Emerson dan Michael Holquist (ed.). Vern W. McGee (terj.). University of Texas: Austin.

Barthes, Roland. (1981). The death of the author. Theory of authorship. Caughie, John (ed.). Routledge: New York. Michael Holquist, Vern W. McGee (terj.).

University of Texas: Austin.

Barry, Petter. (1995). Beginning theory: An introduction to literary and cultural theory. Manchester University Press: New York.

Bell, R. (1993). Translation and translating: Theory and practice. Longman: London Cardwell, S. (2002). Adaptation revisited: televisyen and the classic novel. Manchester University Press: Manchester.

Desmond, John M. dan Peter Hawkes. (2006). Adaptation: studying film and literature. McGraw-Hill: New York. 
Halliday, M.A.K. (2002). On Text and discourse. Webster, Jonathan, J. (ed.). Continuum: London.

Hutcheon, Linda. (2006). The theory of adaptation. Routledge Taylor \& Francis Group: New York.

Ingman, M. (1998). The theatre of storytelling: The prose fiction stage adaptation as social allegory in contemporary British drama. University of Hong Kong: Hong Kong.

Iser, Wolfgang. (1987). The act of reading: A theory of aesthetic response. The John Hopkins Universiti Press: London.

Kassim Ahmad (ed.). (1997). Hikayat Hang Tuah. Yayasan Karyawan dan Dewan Bahasa dan Pustaka: Kuala Lumpur,

Kristeva, Julia. (1980). Desire in language: A semiotic approach to literature and art, (terj.) T. Gora, Alice Jardine dan Leon S. Roudiez (ed.). Columbia University Press: New York.

Noor Azam Shairi. (2006). Kesaksian Wangi. Mingguan Malaysia, Pancaindera, 30 Julai 2006, 14-15.

Riffatere, M. (1978). Semiotics of poetry. Indiana University Press: Bloomington. Sinyard, Neil. (2000). Lids tend to come off: David Lean's film of E. M. Forster's a passage to India. Giddings, Robert \& Erica Sheen (eds.). The classic novel: from page to screen. Manchester University Press: Manchester and New York. Stam, R. (2005). Introduction: the theory and practice of adaptation. R. Stam dan A. Raengo (ed.). Literature and Film: A Guide to the Theory and Practice of Film Adaptation. Blackwell Publishing: Oxford, UK.

Teuku Iskandar. (1995). Kesusasteraan klasik Melayu sepanjang abad. Universiti Brunei Darussalam: Bandar Seri Begawan.

U-Wei Haji Saari. (2010). Wangi jadi saksi. Dewan Bahasa dan Pustaka: Kuala Lumpur.

Received: 10 October 2017

Accepted: 01 November 2017 